\title{
The Effects of Knowledge Sharing on Individual Creativity in Higher Education Institutions: Socio-Technical View
}

\author{
Joosung Lee \\ Division of Interdisciplinary Wellness Studies, Soonchunhyang University, 22 Soonchunhyang-ro, Asan, \\ Chungnam 31538, Korea; jsl@sch.ac.kr; Tel.: +82-41-530-4974
}

Received: 14 May 2018; Accepted: 7 June 2018; Published: 16 June 2018

\begin{abstract}
Knowledge sharing has multifaceted effects on organizations, such as improving work performance, among which creativity is apparently one of the most important parts. Nevertheless, the effects of knowledge sharing on individuals has not been paid attention sufficiently by previous research. Furthermore, knowledge sharing research mainly concerns business organizations rather than public organizations. This study aims to examine the effects of knowledge sharing on individuals in a higher institution of education in Korea, for which a socio-technical view and social capital theory is used to investigate the important antecedents of knowledge contribution, as well as to examine social and technical facets. This study is the first research regarding the relationship between knowledge sharing and individual creativity, and it also identifies the mediating effects of knowledge sharing on individual creativity at an individual level in a higher education institution.
\end{abstract}

Keywords: socio-technical view; individual creativity; knowledge sharing

\section{Introduction}

Knowledge is considered the primary source of competitive advantage (Stewart and Ruckdeschel 1998) and is critical to the long term sustainability and success of the organization (Nonaka and Takeuchi 1995), thus knowledge is one of the most important resources for an organization (Choe 2004). In the recent literature regarding knowledge management, several studies have analyzed critical success factors and barriers, such as organizational culture, affecting knowledge management and the adoption of knowledge management systems (KMSs) (Khan et al. 2015a, 2015b). The crucial role of alignment between enterprise knowledge and KMSs has been suggested (Centobelli et al. 2017), and the impact of knowledge management and KMSs on individual and corporate performance has been identified (Bhatt 2001; Dyer and Hatch 2006).

Against this backdrop, knowledge sharing, which is the central activity of knowledge management, has multifaceted implications and potential benefits for organizations, and the effects of knowledge sharing have been investigated by many previous researchers in multifaceted dimensions. Knowledge sharing is known to be positively related to cost reduction, improvement of efficiency, organization and employee performance, and organizational teamwork (Nonaka and Takeuchi 1995; Hansen 2002; Cummings 2004; Cabrera and Cabrera 2005; and Mesmer-Magnus and DeChurch 2009). Furthermore, effective management of knowledge sharing can promote organizational innovation by supporting organizational members in innovating, collaborating, and making correct decisions efficiently (Nonaka and Takeuchi 1995; Du Plessis 2005).

In today's high risk and ruthless competitive environment, which is faced by each industry, both academic scholars and practitioners have found that continuous innovation is a critical competitiveness that is needed to survive, especially for knowledge base development industries (Mumford 2000; 
Weiner 2000; DiPietro and Anoruo 2006). Additionally, it has been confirmed that organizations are the most likely to succeed in a situation when they truly recognize individual creativity and focus on nurturing and promoting creativity (Williamson 2001), as creativity is the foundation of innovation (Dewett and Gruys 2007). Individual creativity can be used as building blocks for organizational innovation, change, and competitiveness (Mumford 2000; Williamson 2001; Zhou and George 2001; DiPietro and Anoruo 2006), as an individual is always regarded as the source of a novel idea of an organization (Gilad 1984; Whiting 1988; Mumford 2000), which is the basic element of an organization's creative and innovative potential (Amabile 1988; Shalley 1995).

Nevertheless, the effects of knowledge sharing on individuals have not been paid enough attention by previous research (Quigley et al. 2007). Based on the previous research regarding creativity, to improve creativity, there are multiple approaches, amongst which the most frequently cited one is to continually educate individuals on their capacity for generating new knowledge, discovering applications, and maintaining the knowledge for future applications (Chen and Chen 2010; Gardner and Laskin 2011). Higher education represents the basic capacity of innovation, and the key driver of national economic competitiveness and development quality. Thus, higher education is currently getting much attention from practitioners and government agencies (Fairweather 2000; Meek 2000; Chen and Chen 2010). Higher education institutions' mission is to create and transfer knowledge, which includes explicit and tacit knowledge. It is imperative that students in the higher education institutions consciously or subconsciously share knowledge with others in both formal communities (teamwork or research project) and informal communities (Petrides and Nodine 2003). Thus, knowledge sharing is gaining much attention in higher education institutions, as well as for its information practices and learning strategies, particularly in developed countries, which have been receiving grants to implement knowledge management practices (Sohail and Daud 2009).

From the absence of understanding about the current approach regarding the relationship between knowledge sharing and individual creativity in a higher education institution case, this research develops an integrative model to explain the effects of knowledge sharing on individual creativity. The study draws on both a socio-technical view and social capital theory to investigate the important antecedents of knowledge sharing, as well as examining the social and technical factors on individual creativity through the mediating effects of knowledge sharing. Accordingly, the study should make a theoretical fit of a socio-technical view and social capital theory in the knowledge sharing and individual creativity context. After developing the preceding factors, related factors are linked to perceived knowledge sharing and individual creativity extent, and then each variable and path to examine the mediating effects of knowledge sharing on individual creativity is verified.

This paper makes four key contributions. Firstly, to the best of the authors' knowledge, it is the first research regarding the relationship between knowledge sharing and individual creativity, while previous studies have only focused on the effects of knowledge sharing on organizational performance. With this new perspective on knowledge sharing, this study is expected to establish the first research literature of knowledge sharing's effects on individual creativity that has not yet been explored in previous studies. Secondly, this study set knowledge sharing as a mediator between antecedent factors of knowledge sharing and individual creativity. With this improved approach, this model can explain the mediating effects of knowledge sharing on individual creativity, which contributes to both academics and practices, to facilitate individual creativity through knowledge sharing. Thirdly, this study uses socio-technical theory and social capital theory in knowledge sharing effects on individual creativity to propose an improved model of socio-technical view that is suitable for knowledge sharing practices in higher education institutions. Finally, this study focuses on the knowledge sharing practices in a higher education institution. By applying this approach, the study provides a better rationale of understanding the role of knowledge sharing, as well as the relationship between knowledge sharing and individual creativity in higher education institutions. Furthermore, it also indicates abundant theoretical and practical implications for individual creativity improvement through getting knowledge by boosting sharing among members in higher education institutions. 


\section{Theoretical Background}

\subsection{Knowledge Management for Knowledge Sharing and Individual Creativity}

As mentioned above, knowledge management is critical for successfully sharing and utilizing individuals' knowledge at an organization level. This impact of knowledge management and KMSs on individual and corporate performance has been well established (Bhatt 2001; Dyer and Hatch 2006). For this purpose, the alignment between enterprise knowledge and KMSs (Centobelli et al. 2017) is important. Several researchers applied knowledge management to team creativity and to organizational performance improvement. Dong et al. (2017) suggested ways to enhance employee creativity via individual skill development and team knowledge sharing. Son et al. (2017) also examined the impact of close monitoring on creativity and knowledge sharing and found the mediating role of leader-member exchange. Men et al. (2017) investigated when and how knowledge sharing benefitted team creativity, and pointed out the importance of cognitive team diversity.

Knowledge sharing (KS) is part of knowledge management (KM), but sometimes researchers use the terms interchangeably (Kim and Lee 2006; Lee et al. 2010). From the literature review of previous research, the definition of knowledge sharing has not reached an agreement by researchers. This study defines knowledge as ideas, facts, expertise, and judgments that can influence individual, team, and organizational performance (Bartol and Srivastava 2002), and information is considered as the source of this knowledge. Thus, the concepts that are presented in this study are closely related to effective KMS development as an organizational practice, as well as system infrastructure. This is consistent with the fact that Fink and Ploder (2009) and Centobelli et al. (2017) defined KMSs as a combination of knowledge management practices (KM-Practices), that is, a set of methods and techniques to support the organizational processes of KM development on the one hand, and knowledge management tools (KM-Tools), namely specific IT-based systems that support KM-Practices on the other hand.

Knowledge sharing is means to an end, but not an end in itself. Knowledge is a critical organizational resource and knowledge sharing can raise the sustainable competitiveness of an organization (Davenport and Prusak 2000; Foss and Pedersen 2002). Among many means of knowledge-based resources, knowledge sharing can help members and teams to exploit knowledge-based resources, and capitalize on them, which will contribute to the competitiveness of an organization (Davenport and Prusak 2000; Cabrera and Cabrera 2005; Jackson et al. 2006). Among the multiple benefits of knowledge sharing, the most important effect of knowledge sharing should be related to organizational creativity and innovation, because knowledge sharing does not only mean reorganization and effective transfer of knowledge, skills, and information, but it also indicates the creation of new knowledge and innovative ideas (Cabrera and Cabrera 2005).

Creativity needs several resources to be realized, for instance, time, materials, teamwork effort, a great deal of hard work, knowledge resources, and strenuous mental energy. Among them, knowledge can be viewed as an important resource that facilitates individual creativity. Knowledge sharing among members in organization can share knowledge and information, which is an essential source for individual creativity (Shalley et al. 2004).

Although there is some research that indicates that knowledge sharing has positive relationship with individual creativity, there is not much actual research investigating the relationship between knowledge sharing and individual creativity.

\subsection{Socio-Technical View on Knowledge Sharing}

The main idea of the socio-technical view is that an organization is composed of a social sub-system and technical sub-system. An organization is a sophisticated system, and sub-systems are needed in order for it to work harmoniously. Therefore, social and technical sub-systems, as two key functions of an organization, need to be considered interactively to maintain continuous improvement (Bostrom and Heinen 1977). Table 1 shows the definition and examples of social and technical sub-systems. 
Table 1. Social and technical subsystems.

\begin{tabular}{ll}
\hline \multicolumn{1}{c}{ Sub-Systems } & \multicolumn{1}{c}{ Definitions and Examples } \\
\hline Social sub-system & $\begin{array}{l}\text { The social part of an organization, for example, attitude, knowledge, values, } \\
\text { skills, motivation, work atmosphere, and organizational structures. }\end{array}$ \\
\hline Technical sub-system & $\begin{array}{l}\text { The technical part of an organization that improves organizational } \\
\text { performance, for example, devices, tools, and techniques. }\end{array}$ \\
\hline
\end{tabular}

Previous research on socio-technical views is mainly about knowledge sharing, especially in business sectors, but in public sectors, like higher education institutions, there is not much relative research. There are many contextual factors that facilitate knowledge sharing, based on previous research, many of them can be classified into the socio-technical factors.

In recent years, much of the knowledge sharing research has adopted an integrated socio-technical perspective on knowledge sharing, which concentrates on the interactive role of social and technical factors. For instance, the socio-technical perspective is utilized in conceptual research that investigates the contextual factors of knowledge sharing in a specific company (Pan and Scarbrough 1998). Other research of the socio-technical perspective is summarized in Tables 2 and 3.

Table 2. Discriminant validity: correlations and average variance extracted (AVE).

\begin{tabular}{|c|c|c|c|c|c|c|c|c|c|}
\hline Variable & AVE & SIT & SI & IT & EF & SDU & IKS & QKS & IC \\
\hline Social Trust (ST) & 0.614387 & 0.7835 & & & & & & & \\
\hline Social Interaction Ties (SIT) & 0.69128 & 0.320629 & 0.831432 & & & & & & \\
\hline Social Identification (SI) & 0.709861 & 0.182286 & 0.528636 & 0.842532 & & & & & \\
\hline End-user Focus (EF) & 0.658468 & 0.219714 & 0.114117 & 0.098641 & 0.139565 & 0.81146 & & & \\
\hline Smart Device Utilization (SDU) & 0.636148 & 0.307299 & 0.114412 & 0.201135 & 0.632071 & 0.227027 & 0.791295 & & \\
\hline Intensity of Knowledge Sharing (IKS) & 0.701408 & 0.280467 & 0.437818 & 0.350336 & 0.173657 & 0.078168 & 0.339639 & 0.837501 & \\
\hline
\end{tabular}

Table 3. Hypotheses testing results.

\begin{tabular}{ccc}
\hline Hypotheses & T-Value & Result $($ Two Tails) \\
\hline H1a & 0.571489 & Not supported \\
H1b & 2.291318 & Supported $(p<0.05)^{*}$ \\
H2a & 2.282699 & Supported $(p<0.05)^{*}$ \\
H2b & 1.9643 & Supported $(p<0.05)^{*}$ \\
H3a & 0.774949 & Not supported \\
H3b & 2.106269 & Supported $(p<0.05)^{*}$ \\
H4a & 1.979202 & Supported $(p<0.05)^{*}$ \\
H4b & 0.346368 & Not supported \\
H5a & 0.374359 & Not supported \\
H5b & 1.796683 & Supported $(p<0.1)$ \\
H6a & 1.966251 & Supported $(p<0.05)^{*}$ \\
H6b & 0.428985 & Not supported \\
H7a & 0.079318 & Not supported \\
H7b & 2.0156138 & Supported $(p<0.05) *$ \\
\hline
\end{tabular}

\subsection{Social Capital Theory}

Nahapiet and Ghoshal (1998) defined social capital as "the sum of the actual and potential resources embedded within, available through, and derived from the network of relationships possessed by an individual or social unit". Social capital theory is mainly about a perspective that regards social relationships as productive resources (Chiu et al. 2006).

Based on the empirical research (Nahapiet and Ghoshal 1998; Tsai and Ghoshal 1998), social capital has proved to facilitate organizational innovation and resource exchange. In terms of knowledge sharing, 
Bergami and Bagozzi (2000) found that social capital had positive influence on knowledge attainment and exploitation in technology-based firms. Besides the traditional organization, the research of social capital in networks has been investigated by many researchers. Wasko and Faraj (2005) examined the effects of social capital and motivation on knowledge management in a virtual electronic practice.

However, higher education institutions are different from other organizations in terms of organizational structure and culture, as well as interactions among students, which are more dynamic. Consequently, it is still unclear what the effects of social capital on knowledge sharing involving knowledge management and resource exchange in higher education institution are (Ellison et al. 2007).

\section{Hypotheses}

Based on the theoretical support regarding the effect that social and technical factors affect knowledge sharing and that knowledge sharing affects individual creativity, a research model has been developed and the following hypotheses have been proposed. See Figure 1.

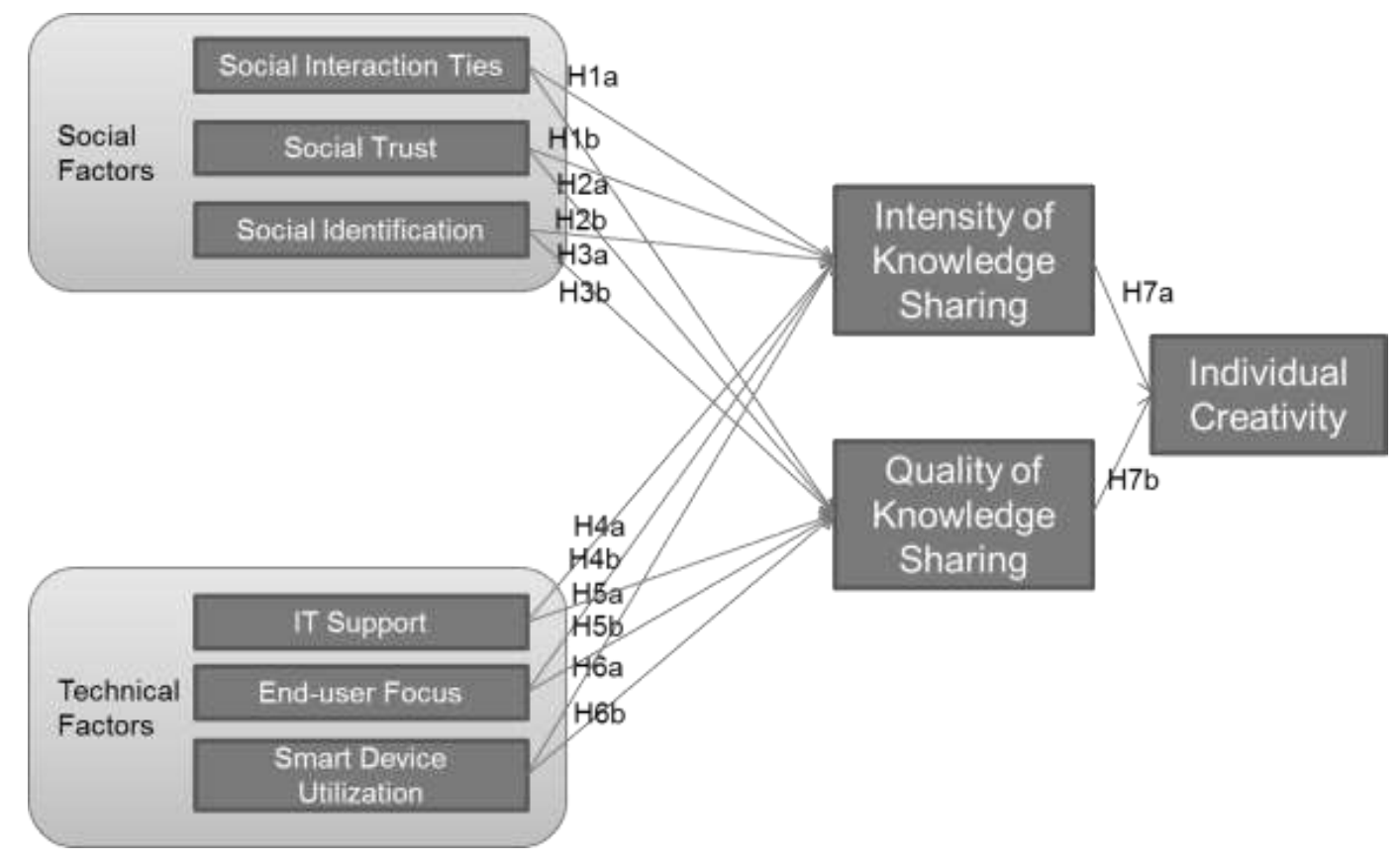

Figure 1. Research model.

\subsection{Social Factors and Knowledge Sharing}

\subsubsection{Social Interaction Ties}

Social interaction ties, as information channels and resource flows (Tsai and Ghoshal 1998), can provide more channels for knowledge sharing among members in an organization (Nahapiet and Ghoshal 1998). Social networks in the organization must facilitate communication among members, in order to improve the capabilities of knowledge sharing (Kim and Lee 2006).

From the point of social capital theory, social interaction ties provide access to knowledge resource by giving opportunities for an exchange of knowledge (Nahapiet and Ghoshal 1998). Furthermore, recent studies proved that social interaction ties had a positive influence on the unit resource combination and exchange (Cabrera and Cabrera 2005), thus, knowledge sharing could be promoted, so members could acquire more knowledge. Chiu et al. (2006) examined the positive social interaction ties' effects on knowledge sharing, which indicated that people who had more social interaction ties tended to participate more actively in knowledge sharing. Participating in knowledge sharing activities 
not only expanded the access to knowledge resources, but it also gave more opportunities to interact with other members. Accordingly, Hypotheses $1 \mathrm{a}$ and $1 \mathrm{~b}$ are given, as follows:

Hypothesis 1a (H1a). An individual's perceived social interaction ties are positively associated with their intensity of knowledge sharing.

Hypothesis $\mathbf{1 b}(\mathbf{H 1 b})$. An individual's perceived social interaction ties are positively associated with their quality of knowledge sharing.

\subsubsection{Social Trust}

Many previous researchers have argued that social trust is an important enabler for knowledge sharing, because it helps members in an organization to overcome barriers and intentions, so as to start knowledge sharing activities more easily (Butler and Murphy 2007). Krogh (1998) indicated that trust as a kind of organizational culture could enhance communication speed, because members with high trust toward others could share knowledge and information without hesitation, thus activating knowledge sharing. Moreover, there were also several empirical studies that directly proved that trust could lead to better knowledge sharing (Nonaka and Takeuchi 1995; Chiu et al. 2006; Kim and Lee 2006). Without trust, individuals were reluctant to share knowledge with others, both in formal and informal knowledge sharing practices (Andrews and Delahaye 2000).

Therefore, trust was a particularly significant variable for facilitating knowledge sharing. Blau (1964) believed that trust was essential for creating and maintaining relationships for knowledge sharing, and led to a good quality of knowledge sharing. Accordingly, Hypotheses $2 \mathrm{a}$ and $2 \mathrm{~b}$ are given, as follows:

Hypothesis 2a (H2a). An individual's perceived social trust is positively associated with their intensity of knowledge sharing.

Hypothesis $\mathbf{2 b}(\mathbf{H} \mathbf{2} \mathbf{b})$. An individual's perceived social trust is positively associated with their quality of knowledge sharing.

\subsubsection{Social Identification}

People with a high level of emotional identification have a high level of loyalty and belongingness towards organizations, and also show willingness to maintain committed relationships and helpful behaviors with the organizational members. From the perspective of social capital theory, Nahapiet and Ghoshal (1998) indicated that identification was a social capital resource that could change members' motivation to share knowledge. This finding also coincided with the fact that a high level of personal networks were always associated with a strong and positive social identification in an organization (Bartol and Srivastava 2002). On the contrary, contradictory and negative identities toward an organization would make barriers for members to share knowledge and information. Accordingly, Hypotheses $3 \mathrm{a}$ and $3 \mathrm{~b}$ are given, as follows:

Hypothesis 3a (H3a). An individual's perceived social identification is positively associated with their intensity of knowledge sharing.

Hypothesis $3 \mathbf{b}(\mathbf{H} 3 \mathbf{b})$. An individual's perceived social identification is positively associated with their quality of knowledge sharing. 


\subsection{Technical Factors and Knowledge Sharing}

\subsubsection{IT Support}

IT support has been a platform for effective knowledge management, and it has also been a foundation for knowledge sharing. IT support here meant an integrated IT infrastructure with Intranet, Internet, hardware, software, and databases. IT support was not only reflected from the IT infrastructure of an organization, but it has also been related to utilization by users. Many researchers have argued that IT utilization has been a fundamental and critical enabler for knowledge sharing (Machlup 1984; Davenport and Prusak 2000). IT infrastructure has played key role as knowledge management system (KMS) in the knowledge sharing process, which is a foundation for knowledge management, and many researchers have examined the positive effects of IT support on knowledge sharing capabilities (Kim and Lee 2006). Accordingly, Hypotheses $4 \mathrm{a}$ and $4 \mathrm{~b}$ are given, as follows:

Hypothesis 4a (H4a). An individual's perceived IT support is positively associated with their intensity of knowledge sharing.

Hypothesis $\mathbf{4 b}(\mathbf{H} 4 \mathbf{b})$. An individual's perceived IT support is positively associated with their quality of knowledge sharing.

\subsubsection{End-User Focus}

The importance of end-user focus for technology-based instruments or applications is the focused of much research (Davenport and Prusak 2000; Butler and Murphy 2007). Effective knowledge sharing requires IT utilization to be integrative, easy to use, easy to access, and searchable (Bartol and Srivastava 2002). In addition, technical systems are required to update fast and to be easy-to-use, in order to allow users to actively access to knowledge sharing activities (Durst 1999; Gardner and Laskin 2011). Hypotheses $5 \mathrm{a}$ and $5 \mathrm{~b}$ are given, as follows:

Hypothesis 5a (H5a). An individual's perceived end-user focus is positively associated with their intensity of knowledge sharing.

Hypothesis $\mathbf{5 b}(\mathbf{H} 5 \mathbf{b})$. An individual's perceived end-user focus is positively associated with their quality of knowledge sharing.

\subsubsection{Smart Device Utilization}

Smart devices, alternatively called ubiquitous devices, can be viewed as computer-based devices, which ultimately are used for getting information from networks. Through the utilization of smart devices, the Internet has been linked both to increases and decreases in knowledge sharing. Nowadays, smart devices are used broadly in the university, in order to check webpages, SNSs, e-mail, and other activities, all of which are online knowledge sharing activities. Thus, the smart device has become important platform of knowledge sharing, besides the computer (Ellison et al. 2007). Accordingly, Hypotheses $6 \mathrm{a}$ and $6 \mathrm{~b}$ are given, as follows:

Hypothesis 6a (H6a). An individual's perceived smart device utilization is positively associated with their intensity of knowledge sharing.

Hypothesis $\mathbf{6 b}(\mathbf{H 6 b})$. An individual's perceived smart device utilization is positively associated with their quality of knowledge sharing. 


\subsection{Knowledge Sharing and Individual Creativity}

Members in organization may get creative ideas when they share their ideas with others and when they discuss ideas. Lee et al. (2011) argued that knowledge sharing was a critical facilitator of creative ideas, and was a primary factor to facilitate organizational creativity and innovation. Furthermore, knowledge sharing could also stimulate individual creativity (Chen and Chen 2010), because knowledge sharing could help collaboration within an organization, and could also improve the domain knowledge (Amin et al. 2011). All of this could be explained by the fact that the knowledge resource is the most important factor for facilitating individual creativity. By knowledge sharing, people can get high quality knowledge and information, and combine them with their own knowledge, which would finally result in creative ideas and new knowledge (Amin et al. 2011). Accordingly, Hypotheses $7 \mathrm{a}$ and $7 \mathrm{~b}$ are given, as follows:

Hypothesis 7a (H7a). An individual's perceived intensity of knowledge sharing is positively associated with their individual creativity.

Hypothesis $7 \mathbf{b}(\mathbf{H 7 b})$. An individual's perceived quality of knowledge sharing is positively associated with their individual creativity.

\section{Research Methodology}

\subsection{Survey Methodology}

There were 213 samples that were selected for the first data analysis among the KAIST (Korea Advanced Institute of Science and Technology) students. From them, 9 of the 213 samples were excluded because of the incomplete and unsatisfied responses. Therefore, 204 samples were selected for the final data analysis.

\subsection{Measurement Items}

The questionnaire was conducted with a multi-item method, and each item was measured based on the seven-point Likert scale, ranging from 'strongly disagree' to 'strongly agree'. The measurement items that were used to operationalize the construct were adopted from the relevant prior studies; they had already been validated in other prior literature. The questionnaire for this research is shown in the Appendix A.

This study was comprised of six independent variables, two mediating variables, and one dependent variable.

Among them, the independent variables were divided into two dimensions, the social and technical. The social dimension consisted of three variables, namely, social interaction ties, social trust, social identification, and the technical dimension was composed of IT support, end-user focus, and smart device utilization. The social interaction ties were based on the studies of Tsai and Ghoshal (1998) and Chiu et al. (2006). Social trust and identification were modified from the researches of Chiu et al. (2006). The items for IT support were based on Kim and Lee (2006), and the items of the end-user focus were modified from the work of Kim and Lee (2006). Finally, smart device utilization was a new item that was based on self-developed items.

In terms of the mediating and dependent variables, intensity and quality of knowledge sharing were relatively based on the research of Chiu et al. (2006) and Kim and Lee (2006). Finally, the items that were developed to measure the individual creativity were from Scott and Bruce (1994), and Zhou and George (2001). 


\subsection{Data Analysis}

The data analysis in this study was performed using the PLS (partial least square) method and several other statistical methods. The application of the statistical methods followed the reliability and validity test, the assessment of the measurement model, and the assessment of the structural model.

Firstly, confirmatory factor analysis (CFA) was applied so as to test the adequacy of the measurement model, which was assessed on the criteria of the model fit, convergent validity, and discriminant validity

Cronbach's alpha was used to assess the internal reliability. The value of Cronbach's alpha ranged from 0.70 to 0.88 , which exceeded the Nunnally's criterion of 0.7 . To check the convergent validity, a confirmatory factor analysis (CFA) was conducted and it checked the parameter estimates and their associated $t$-values. All of the measurement items were valid $(p<0.001)$ and higher than 0.7 , which also demonstrated unidimensionality. The composite reliability (CR) was also checked, the lowest value of $C R$ was above 0.83 , which exceeded the recommended value of 0.7 . The average variance extracted (AVE) was also calculated and each AVE was above 0.6, exceeding the threshold value of 0.5 .

The discriminant validity was assessed so as to evaluate whether the measures of the constructs were distinct and whether the indicators were loaded on the appropriate construct. The square root of the AVE was checked to be greater than all of the inter-construct correlations, which presented evidence of sufficient discriminant validity (Chin 1998). Table 2 shows that the diagonal elements, the square root of AVE, were greater than their corresponding off-diagonal elements.

The detailed hypotheses testing results are presented in Table 3. Among the 14 hypotheses, most were supported. The variance explained (R2) by the paths was examined and the results are presented in Table 4 . The $\mathrm{R} 2$ for the final dependent variable, individual creativity, was 0.63 . Additionally, the R2 for the quality of knowledge sharing, which was the most important independent factor influencing individual creativity, was 0.82 . The $\mathrm{R} 2$ value indicated that the model explained a substantial amount of variance for the online knowledge contribution.

Table 4. R square.

\begin{tabular}{cccc}
\hline & Intensity of Knowledge Sharing & Quality of Knowledge Sharing & Individual Creativity \\
\hline R Square & 0.29832 & 0.56642 & 0.308347 \\
\hline
\end{tabular}

\section{Discussion}

\subsection{Summary of Results}

After the empirical analysis, a rich set of results were obtained. The most important result was that the quality of knowledge sharing was positively associated with individual creativity and played a mediating role between socio-technical factors and individual creativity, however the intensity of knowledge sharing was not.

Firstly, the results indicated that social interaction ties, IT support, and end-user focus were positively associated with intensity of knowledge sharing, and that the social interaction ties, social trust, social identification, and smart device utilization were positively associated with quality of knowledge sharing. The social interaction ties increased the individuals' intensity of knowledge sharing. This finding was similar to Tsai and Ghoshal (1998), who found that social interaction ties had a strong effect on trust in the context of resource exchange and production innovation within the organization. Social trust and social identification did not have a significant impact on intensity of knowledge sharing, but had an impact on the intensity of knowledge sharing. One possible explanation might have been that individuals were willing to share their personal knowledge because of the close and frequent interaction among members, fairness in exchanging knowledge, and strong feelings toward university, without necessarily trusting other members in the university. 
Another possible explanation was that trust and social identification were not crucial in less risky knowledge sharing relationships.

Secondly, IT support and end-user focus were positively associated with intensity of knowledge sharing, but not with the quality of knowledge sharing. This result coincided with other research that was about the positive effects of IT on knowledge sharing. However, it did not influence the quality of knowledge sharing, which meant that IT support and end-user focus were not enablers of the quality of knowledge sharing. It could have been explained by the fact that IT infrastructure was a platform of knowledge sharing, but did not influence the quality of knowledge sharing, which was more related to the knowledge sharers' motivation. However, on the contrary of the expectation, smart device utilization was positively associated with the quality of knowledge sharing, but not with the intensity of knowledge sharing. One explanation was that the smart device had the mobility that could help students to find the knowledge timely and appropriately, which increased quality of knowledge sharing. On the other hand, the individuals' smart device utilization did not change the perceived intensity of knowledge sharing.

Finally, the quality of knowledge sharing had mediating effects, as shown in Table 4 . The results showed that the quality of knowledge sharing played a strong mediating role between those social and technical factors and individual creativity. It meant that individual creativity could be improved through visible support by increasing the members' social networks, building a culture of trust and identification, and encouraging the use of a smart device for knowledge sharing.

Additionally, by examining the relationship between knowledge sharing and individual creativity, an individual's flow through knowledge sharing was enabled. According to the results, the quality of knowledge sharing was the major factor that facilitated individual creativity, rather than the intensity of knowledge sharing. It indicated that quality was more important than intensity or volume, in terms of knowledge.

\subsection{Limitations and Future Research}

First, the definition of creativity that was used in this research was very generalized. In fact, creativity could be classified with many dimensions and categories. Thus, future research could make contributions by investigating the effects of knowledge sharing on a different creativity.

Based on the facts that there was limited research on the effects of knowledge sharing on an individual level, this research focused on individual creativity. However, further research should notice that individual creativity is one of the most antecedents of organizational innovation and performance. Thus, it was very important to understand how knowledge sharing improved organizational performance through individual creativity.

There could have been a sample bias inherent in most of the online survey-based research. As the survey was conducted on the Internet using a self-motivated questionnaire, on people who were very active and altruistic, and this may have biased the results.

Because the survey was only conducted among the KAIST students, KAIST was the only sample organization. The results could be different in relation to the way knowledge sharing took place, as this result was not able to be generalized into various types of higher education institutions. Future research that would compare different types of services may be needed.

\subsection{Implications for Theory and Practice}

\subsubsection{Theoretical Implication}

The effects of knowledge sharing have been discussed in many previous studies, but they were mainly focused on organizational performance. However, in terms of creativity and innovation, there was limited literature available to explore. The relationship between knowledge sharing and individual creativity was, firstly, investigated in this study with the socio-technical view on knowledge sharing. This study was theoretically important, because it bridged the gap between knowledge sharing with 
individual creativity, which had thorough backgrounds. By developing the research model under the socio-technical view, a strong framework was offered for explaining knowledge sharing's effects on individual creativity.

This study was important as it was the first research article that investigated the relationship between knowledge sharing and individual creativity. Theoretically, this was a pioneering study that adopted a socio-technical theory and a social capital theory into the effects of knowledge sharing on individual creativity research. This was a theoretically important contribution, because the socio-technical theory was used frequently in recent research on knowledge sharing. Focusing on the integrative effect of social and technical factors on knowledge sharing, this gaves shape to causal relationships and the path from major components of socio-technical factors to individual creativity through knowledge sharing. By adopting this model, the social interaction ties, social trust, social identification, and smart device utilization could contribute to individual creativity through the quality of knowledge sharing.

Moreover, it was important to clarify whether the intensity of knowledge sharing or the quality of knowledge sharing, and the results showed that the quality of knowledge sharing only had mediating effect between socio-technical factors and individual creativity. This finding established the exact difference in intensity and quality of knowledge sharing, and figured out the quality sides' important mediating role. This study found that the antecedent factors of knowledge sharing could boost individual creativity.

This study also made up the limitation of knowledge sharing in the public sector, especially in higher education institutions, where individual creativity was especially important. Accordingly, the results better explained the knowledge sharing's effects on individual creativity in a higher education institution. This empirical study on real contributors will enrich the understanding of both knowledge sharing and individual creativity.

\subsubsection{Practical Implication}

Our findings offered guidance and insights for practitioners and leaders who were trying to boost individual creativity. As the individual creativity was an important source of organization, and knowledge sharing could contribute to the individual creativity, more specifically, the more qualified knowledge was attained from knowledge sharing, the more the individual creativity improved. Through this study, socio-technical factors were suggested for practitioners and academics in higher education systems to focus on. Particularly, the practitioners needed to strive to increase the quality of knowledge sharing so as to boost individual creativity.

Among the social factors, social interaction ties, social trust, and social identification, all had increased the individual creativity through the quality of knowledge sharing. Thus, higher education institutions should focus more on the social capital inside the organization, so as to make an appropriate environment for individual creativity, which would finally contribute to the organization level innovation and improve the performance of the organization. This social capital could be raised up by the intended support of organizations. For instance, the university should support formal and informal communities inside the university, to let the students make more social interaction ties. The increase in social interaction ties would result in the knowledge 'gateway' of individuals, to make knowledge sharing smoother and increase the chance to find qualified knowledge. Social trust and social identification could be cultivated by the organizational culture, for instance, organizational history has been an important aspect of organizational culture, which was found to increase the members' belongingness and the trust among the members. That was why many famous universities collected the history of the university and reorganized the history for differentiating the history of universities for contributing to forming its specific culture. Based on our study, these activities were not only contributing to the belongings and culture of universities, but it also contributed to individual creativity through knowledge sharing. Thus, universities should make use of this social capital to 
making contributions to qualified knowledge sharing, and to increase individual creativity, which finally contributed to the individuals' and organizational performance.

Among the technical factors, only the smart device utilization was related to the quality of knowledge sharing. However, it did not ignore the importance of IT support and end-user focus, which played an important role in forming the platform of knowledge sharing. However, IT support and end-user focus mainly contributed to the intensity of knowledge sharing, not the quality of knowledge sharing, which could be explained by the fact that KAIST already had enough IT support and end-user focus that they were not critical factor for the quality of knowledge sharing. While smart device utilization was the new factor in creativity research, results showed that it was positively related to creativity by the mediating effect of knowledge sharing, thus organizations should diffuse the smart devices to allow members access to knowledge sharing process, to increase their creativity. However, the smart device was not only related to knowledge sharing among the organization, thus organizations also had to regulate the utilization of the smart device for knowledge gain and sharing, such as encouraging access to the organization related resources and online community, but also by restricting accessing to entertainment or SNS that was not related to the organizational knowledge sharing.

Finally, the implications for firms and/or policy makers were that the social capital formation within an organization was important for knowledge sharing. That is, an organizational culture that built social trust and interaction ties should be fostered. Microsoft, for example, has been able to increase its new product development and financial performance significantly by innovating its organizational culture of social trust and knowledge sharing. Such organizational culture policies are necessary to support the competitiveness of education systems, improving the knowledge management processes. This study found that, to increase individual creativity, the quality of knowledge sharing should be getting more attention instead of just encouraging students to share more knowledge.

Acknowledgments: This work was supported by Soonchunhyang University Research Grant No. 20180408.

Conflicts of Interest: The author declares no conflict of interest.

\section{Appendix A}

Table A1. Measurement items. KAIST-Korea Advanced Institute of Science and Technology.

\begin{tabular}{|c|c|c|}
\hline \multirow{4}{*}{ Social Interaction Ties } & $\begin{array}{l}\text { I maintain close social relationships with some members in the } \\
\text { university community. }\end{array}$ & \multirow{4}{*}{$\begin{array}{l}\text { (Tsai and Ghoshal 1998) } \\
\text { (Chiu et al. 2006) }\end{array}$} \\
\hline & $\begin{array}{l}\text { I spend a lot of time interacting with some members in the university } \\
\text { community. }\end{array}$ & \\
\hline & I know some members in the university community on a personal level. & \\
\hline & $\begin{array}{l}\text { I have frequent communication with some members in the university } \\
\text { community. }\end{array}$ & \\
\hline \multirow{3}{*}{ Social Trust } & I believe that other members in KAIST are honest and reliable. & \multirow{3}{*}{$\begin{array}{c}\text { (Gefen et al. 2003; Cabrera } \\
\text { and Cabrera 2005) } \\
\text { (Chiu et al. 2006) }\end{array}$} \\
\hline & $\begin{array}{l}\text { I believe that other members in KAIST are knowledgeable and } \\
\text { competent in their area. }\end{array}$ & \\
\hline & I expect that students in my personal network will help each other. & \\
\hline
\end{tabular}


Table A1. Cont.

\begin{tabular}{|c|c|c|}
\hline \multirow{4}{*}{ Social Identification } & I believe I am similar to my friends in KAIST. & \multirow{4}{*}{$\begin{array}{l}\text { (Cabrera and Cabrera 2005) } \\
\quad \text { (Chiu et al. 2006) }\end{array}$} \\
\hline & I am happy to spend time with the group of my friends. & \\
\hline & $\begin{array}{c}\text { I perceive an overlap between my self-identity and my friends group in } \\
\text { KAIST. }\end{array}$ & \\
\hline & I feel feelings of belongingness towards the group of my friends. & \\
\hline \multirow{3}{*}{ IT support } & The KAIST's IT infrastructure facilitates knowledge sharing. & \multirow{3}{*}{ (Kim and Lee 2006) } \\
\hline & Knowledge/ information available in the KAIST's IT is relevant. & \\
\hline & Knowledge/ information available in the KAIST's IT is up-to-date. & \\
\hline \multirow{3}{*}{ End-user Focus } & I regularly use the Internet, e-mail, and the organization's intranet & \multirow{3}{*}{ (Kim and Lee 2006) } \\
\hline & In KAIST, IT infrastructure is designed to be user-friendly & \\
\hline & It is easy for me to use IT infrastructure without extra training. & \\
\hline \multirow{4}{*}{ Smart Device Utilization } & $\begin{array}{l}\text { In the past week, on average, approximately how many minutes per } \\
\text { day have you spent on smart device? }\end{array}$ & \multirow{4}{*}{ (Ellison et al. 2007) } \\
\hline & Smart device has become part of my daily routine. & \\
\hline & I feel out of touch when I do not have smart device for a while. & \\
\hline & I would be sorry if smart device shut down. & \\
\hline \multirow{3}{*}{$\begin{array}{l}\text { Intensity of Knowledge } \\
\text { Sharing }\end{array}$} & In KAIST, knowledge is shared frequently among members. & \multirow{3}{*}{ (Chiu et al. 2006) } \\
\hline & Members share their knowledge and expertise voluntarily in KAIST. & \\
\hline & Members share knowledge with people from other divisions in KAIST. & \\
\hline \multirow{6}{*}{ Quality of Knowledge Sharing } & The knowledge shared by members in KAIST is relevant to the topics. & \multirow{6}{*}{ (Chiu et al. 2006) } \\
\hline & The knowledge shared by members in KAIST is easy to understand. & \\
\hline & The knowledge shared by members in KAIST is accurate. & \\
\hline & The knowledge shared by members in KAIST is complete. & \\
\hline & The knowledge shared by members in KAIST is reliable. & \\
\hline & The knowledge shared by members in KAIST is timely. & \\
\hline \multirow{4}{*}{ Individual Creativity } & I am a good source of creative ideas. & \multirow{4}{*}{ (Shin and Zhou 2003) } \\
\hline & I come up with new and practical ideas to improve performance. & \\
\hline & I am not afraid to take risks. & \\
\hline & I promote and champion ideas to others. & \\
\hline
\end{tabular}

\section{References}

Amabile, Teresa M. 1988. A model of creativity and innovation in organizations. Research in Organizational Behavior 10: 123-67.

Amin, Aamir, Shuib Basri, Mohd Fadzil Hassan, and Mubashir Rehman. 2011. Occupational stress, knowledge sharing and GSD communication barriers as predictors of software engineer's creativity. Paper presented at 2011 IEEE International Conference on Industrial Engineering and Engineering Management (IEEM), Singapore, 6-9 December.

Andrews, Kate M., and Brian L. Delahaye. 2000. Influences on knowledge processes in organizational learning: The psychosocial filter. Journal of Management Studies 37: 797-810. [CrossRef]

Bartol, Kathryn M., and Abhishek Srivastava. 2002. Encouraging knowledge sharing: The role of organizational reward systems. Journal of Leadership E Organizational Studies 9: 64-76.

Bergami, Massimo, and Richard P. Bagozzi. 2000. Self-categorization, affective commitment and group self-esteem as distinct aspects of social identity in the organization. British Journal of Social Psychology 39: 555-77. [CrossRef] [PubMed]

Bhatt, Ganesh D. 2001. Knowledge management in organizations: examining the interaction between technologies, techniques, and people. Journal of Knowledge Management 5: 68-75. [CrossRef]

Blau, Peter M. 1964. Exchange and Power in Social Life. New York: Transaction Publishers.

Bostrom, Robert P., and J. Stephen Heinen. 1977. MIS Problems and failures: a sociotechnical perspective part I: The cause. MIS Quarterly 1: 17-32. [CrossRef]

Butler, Tom, and Ciaran Murphy. 2007. Understanding the design of information technologies for knowledge management in organizations: a pragmatic perspective. Information Systems Journal 17: 143-63. [CrossRef] 
Cabrera, Elizabeth F., and Angel Cabrera. 2005. Fostering knowledge sharing through people management practices. The International Journal of Human Resource Management 16: 720-35. [CrossRef]

Centobelli, Piera, Roberto Cerchione, and Emilio Esposito. 2017. Knowledge management in startups: systematic literature review and future research agenda. Sustainability 9: 361. [CrossRef]

Chen, Jui-Kuei, and I-Shuo Chen. 2010. Critical creativity criteria for students in higher education: taking the interrelationship effect among dimensions into account. Quality \& Quantity 46: 1057-75.

Chin, Wynne W. 1998. The partial least squares approach for structural equation modeling. Modern Methods for Business Research 295: 295-336.

Chiu, Chao-Min, Meng-Hsiang Hsu, and Eric T. G. Wang. 2006. Understanding knowledge sharing in virtual communities: An integration of social capital and social cognitive theories. Decision Support Systems 42: 1872-88. [CrossRef]

Choe, Jong-min. 2004. The consideration of cultural differences in the design of information systems. Information $\mathcal{E}$ Management 41: 669-84.

Cummings, Jonathon N. 2004. Work groups, structural diversity, and knowledge sharing in a global organization. Management Science 50: 352-64. [CrossRef]

Davenport, Thomas H., and Laurence Prusak. 2000. Working Knowledge: How Organizations Manage What They Know. Boston: Harvard Business Press.

Dewett, Todd, and Melissa L. Gruys. 2007. Advancing the case for creativity through graduate business education. Thinking Skills and Creativity 2: 85-95. [CrossRef]

DiPietro, William R., and Emmanuel Anoruo. 2006. Creativity, innovation, and export performance. Journal of Policy Modeling 28: 133-39. [CrossRef]

Dong, Yuntao, Kathryn M. Bartol, Zhi-Xue Zhang, and Chenwei Li. 2017. Enhancing employee creativity via individual skill development and team knowledge sharing: Influences of dual-focused transformational leadership. Journal of Organizational Behavior 38: 439-58. [CrossRef]

Du Plessis, Marina. 2005. Drivers of knowledge management in the corporate environment. International Journal of Information Management 25: 193-202. [CrossRef]

Durst, Samantha L. 1999. Assessing the effect of family friendly programs on public organizations. Review of Public Personnel Administration 19: 19-33. [CrossRef]

Dyer, Jeffrey H., and Nile W. Hatch. 2006. Relation-specific capabilities and barriers to knowledge transfers: Creating advantage through network relationships. Strategic Management Journal 27: 701-19. [CrossRef]

Ellison, Nicole B., Charles Steinfield, and Cliff Lampe. 2007. The benefits of Facebook "friends:" Social capital and college students' use of online social network sites. Journal of Computer-Mediated Communication 12: 1143-68. [CrossRef]

Fairweather, James S. 2000. Diversification or homogenization: How markets and governments combine to shape American higher education. Higher Education Policy 13: 79-98. [CrossRef]

Fink, Kerstin, and Christian Ploder. 2009. Knowledge management toolkit for SMEs. International Journal of Knowledge Management 5: 46-60. [CrossRef]

Foss, Nicolai J., and Torben Pedersen. 2002. Transferring knowledge in MNCs: the role of sources of subsidiary knowledge and organizational context. Journal of International Management 8: 49-67. [CrossRef]

Gardner, Howard E., and Emma Laskin. 2011. Leading Minds: An Anatomy of Leadership. New York: Basic Books.

Gefen, David, Elena Karahanna, and Detmar W. Straub. 2003. Trust and TAM in online shopping: An integrated model. MIS Quarterly 27: 51-90. [CrossRef]

Gilad, Benny. 1984. Entrepreneurship: The issue of creativity in the market place. The Journal of Creative Behavior 18: 151-61. [CrossRef]

Hansen, Morten T. 2002. Knowledge networks: Explaining effective knowledge sharing in multiunit companies. Organization Science 13: 232-48. [CrossRef]

Jackson, Susan E., Chih-Hsun Chuang, Erika E. Harden, and Yuan Jiang. 2006. Toward developing human resource management systems for knowledge-intensive teamwork. Research in Personnel and Human Resources Management 25: 27-70.

Khan, Zaheer, Yong Kyu Lew, and Rudolf R. Sinkovics. 2015a. International joint ventures as boundary spanners: technological knowledge transfer in an emerging economy. Global Strategy Journal 5: 48-68. [CrossRef]

Khan, Zaheer, Oded Shenkar, and Yong Kyu Lew. 2015b. Knowledge transfer from international joint ventures to local suppliers in a developing economy. Journal of International Business Studies 46: 656-75. [CrossRef] 
Kim, Soonhee, and Hyangsoo Lee. 2006. The Impact of Organizational Context and Information Technology on Employee Knowledge-Sharing Capabilities. Public Administration Review 66: 370-85. [CrossRef]

Lee, Pauline, Nicole Gillespie, Leon Mann, and Alexander Wearing. 2010. Leadership and trust: Their effect on knowledge sharing and team performance. Management Learning 41: 473-91. [CrossRef]

Lee, Kun Chang, Dae Sung Lee, Young Wook Seo, and Nam Young Jo. 2011. Antecedents of team creativity and the mediating effect of knowledge sharing: bayesian network approach to PLS modeling as an ancillary role. Intelligent Information and Database Systems, 545-55.

Machlup, Fritz. 1984. Knowledge: Its Creation, Distribution, and Economic Significance. Princeton: Princeton University Press.

Meek, V. Lynn. 2000. Diversity and marketisation of higher education: Incompatible concepts? Higher Education Policy 13: 23-39. [CrossRef]

Men, Chenghao, Patrick S. W. Fong, Jinlian Luo, Jing Zhong, and Weiwei Huo. 2017. When and how knowledge sharing benefits team creativity: The importance of cognitive team diversity. Journal of Management $\mathcal{E}$ Organization, 1-18. [CrossRef]

Mesmer-Magnus, Jessica R., and Leslie A. DeChurch. 2009. Information sharing and team performance: A meta-analysis. Journal of Applied Psychology 94: 535-46. [CrossRef] [PubMed]

Mumford, Michael D. 2000. Managing creative people: Strategies and tactics for innovation. Human Resource Management Review 10: 313-51. [CrossRef]

Nahapiet, Janine, and Sumantra Ghoshal. 1998. Social capital, intellectual capital, and the organizational advantage. Academy of Management Review 23: 242-66. [CrossRef]

Nonaka, Ikujiro, and Hirotaka Takeuchi. 1995. The Knowledge-Creating Company: How Japanese Companies Create the Dynamics Of Innovation. Oxford: Oxford University Press.

Pan, Shan L., and Harry Scarbrough. 1998. A socio-technical view of knowledge sharing at Buckman Laboratories. Journal of Knowledge Management 2: 55-66. [CrossRef]

Petrides, Lisa A., and Thad R. Nodine. 2003. KM in Education, Defining the Landscape. Half Moon Bay: The Institute for the Study of Knowledge Management in Education, March.

Quigley, Narda R., Paul E. Tesluk, Edwin A. Locke, and Kathryn M. Bartol. 2007. A multilevel investigation of the motivational mechanisms underlying knowledge sharing and performance. Organization Science 18: 71-88. [CrossRef]

Scott, Susanne G., and Reginald A. Bruce. 1994. Determinants of innovative behavior: A path model of individual innovation in the workplace. Academy of Management Journal 37: 580-607.

Shin, S. J., and J. Zhou. 2003. Transformational leadership, conservation and creativity: Evidence from Korea. Academy of Management Journal 45: 703-714. [CrossRef]

Shalley, Christina E. 1995. Effects of coaction, expected evaluation, and goal setting on creativity and productivity. Academy of Management Journal 38: 483-503.

Shalley, Christina E., Jing Zhou, and Greg R. Oldham. 2004. The effects of personal and contextual characteristics on creativity: Where should we go from here? Journal of Management 30: 933-58. [CrossRef]

Sohail, M. Sadiq, and Salina Daud. 2009. Knowledge sharing in higher education institutions: Perspectives from Malaysia. Vine 39: 125-42. [CrossRef]

Son, Seung Yeon, Duck Hyun Cho, and Seung-Wan Kang. 2017. The impact of close monitoring on creativity and knowledge sharing: The mediating role of leader-member exchange. Creativity and Innovation Management 26: 256-65. [CrossRef]

Stewart, Thomas, and Clare Ruckdeschel. 1998. Intellectual capital: The new wealth of organizations. Performance Improvement 37: 56-59. [CrossRef]

Tsai, Wenpin, and Sumantra Ghoshal. 1998. Social capital and value creation: The role of intrafirm networks. Academy of Management Journal 41: 464-76.

Krogh, Von G. 1998. Care in knowledge creation. California Management Review 40: 133-153. [CrossRef]

Wasko, Molly McLure, and Samer Faraj. 2005. Why should I share? Examining social capital and knowledge contribution in electronic networks of practice. MIS Quarterly 29: 35-57. [CrossRef]

Weiner, Robert Paul. 2000. Creativity \& Beyond: Cultures, Values, and Change. New York: The State University of New York Press.

Whiting, Bruce G. 1988. Creativity and entrepreneurship: How do they relate? The Journal of Creative Behavior 22: 178-83. [CrossRef] 
Williamson, Bill. 2001. Creativity, the corporate curriculum and the future: a case study. Futures 33: 541-55. [CrossRef]

Zhou, Jing, and Jennifer M. George. 2001. When job dissatisfaction leads to creativity: Encouraging the expression of voice. Academy of Management Journal 44: 682-96. 